\title{
MIKA OJAKANGAS
}

\section{HYVINVOINNIN EETOS JA “PASSIIVISEN VÄESTÖN ONGELMA"}

\author{
JuUtas Käkriäinen Pekka KuUsen \\ 6O-LUVUN SOSIAALIPOLITIIKAN VALOSSA*
}

I

Vielä muutama vuosi sitten oli muotia hyökätä hyvinvointivaltiota vastaan sen yritteliäisyyttä tukahduttavien ja kansalaisten taloudellista oma-aloitteisuutta ja aktiivisuutta rajoittavien rakenteiden takia. Hyvinvointivaltio estää "yhteiskunnan spontaanien voimavarojen vapautumista", niin kuin Antti Hautamäki asian esitti (Hautamäki 1993, 134). Se aiheuttaa passiivisuutta eikä suinkaan aitoa hyvinvointia. Kuitenkin juuri passiivisuuden poistaminen ja yhteiskunnan spontaanien voimavarojen vapauttaminen yritteliäisyyden lisääminen ja kansalaisten taloudellisen aktiivisuuden kohottaminen olivat Pekka Kuusen mielessä, kun hän 60 luvun sosiaalipolitiikassaan hahmotteli sosiaalipolitiikan kokonaissuunnitelmaa eli suomalaisen hyvinvointivaltion yhteiskuntapoliittista perustaa. Hänen mielestään yrittäjyyden ja taloudellisen oma-aloitteisuuden esteenä ei kuitenkaan ollut liian vahva valtio vaan köyhyys. Kuuselle köyhyys ja siihen liittyvä toivottomuuden horisontti kulkivat käsi kädessä passiivisuuden kanssa ja niinpä hänen kampanjassaan passiivisuus voitettiin vain aktiivisen valtiollisen väliintulon ja tarkemmin sanoen sosiaalipoliittisen tulon- tasoituksen avulla. Sen avulla "passiivinen päivästä päivään eläjä" muutetaan "aktiiviseksi taloudellisen nousun tavoittelijaksi" (Kuusi, 1961, 57). Tämä osoittaa, että Hautamäen ja Kuusen - spontaanin yhteiskunnan puolestapuhujan ja kasvusuuntautuneen hyvinvointivaltion arkkitehdin - päämäärä on itse asiassa sama: väestön kokonaisaktiviteetin lisääminen.

Eivätkö heidän lähtökohtansa ole kuitenkin päinvastaiset, sikäli kuin Kuusi lähtee liikkeelle valtiosta ja Hautamäki yksilöstä ja hänen omasta edustaan? Ei suinkaan. Kuusenkin lähtökohtana on nimenomaan yksilö ja hänen oma etunsa, "kansalaisen paras" (emt., 18). Molempien iskusana on yksilökeskeisyys, sillä vain yksilö - yritteliäs, omaaloitteinen ja vastuullinen yksilö - voi todella toimia väestön kokonaisaktiviteetin lisäämisen subjektina. Jos aktiivinen yksilö

* Oheinen artikkeli on esitelmä, joka on pidetty hieman eri muodoissa - sekä Tutkijaliiton kesäkoulussa Järvenpään Kalliokuninkaalassa 25-26.8.2000 että symposiumissa The Ethos of Welfare. Metamorphoses and Variations of Governmentality 31.82.9.2000 Helsingin yliopiston valtiotieteellisessä tiedekunnassa. Se perustuu VTT Ilpo Helénin johtaman "Pohjoismaisen hyvinvoinnin eetos" -tutkijaryhmän keväällä 2000 tekemään yhteistyöhön. 
on heidän ystävänsä, passiivisuus on kummankin todellinen vihollinen. Kuusen mukaan passiivinen väestö on kasvusuuntautuneen hyvinvointivaltion suurin ongelma. Tästä syystä valtion on "mobilisoitava jatkuvasti kaikki" mukaan taloudelliseen kasvupyrkimykseen (emt., 59). ${ }^{1}$ Hautamäkikin korostaa yleisen liikekannallepanon olennaisuutta. Hänen mukaansa se ei kuitenkaan ole valtion tehtävä muuten kuin siinä mielessä, että valtion on etenkin julkisen hallinnon osalta kyettävä rajoittamaan itseään siinä määrin, että "spontaani yhteiskunta" löytää sille immanentin "kiihkeän dynamiikkansa” (Hautamäki 1993, 171172). Yhtä kaikki, passiivisuus - kiihkoton toimettomuus - muodostaa sen yhteisen vihollisen, jonka kimppuun nämä kaksi yhteiskuntasuunnittelijaa tomerina käyvät. Mistä tämä viha passiivisuutta kohtaan kumpuaa? Minkä takia passiivinen kansalainen on suljettava ulos yhtä hyvin pohjoismaisesta hyvinvointivaltiosta kuin liberaalista kilpailuvaltiosta, tästä "vapauden valtakunnasta"?

Passiivisen kansalaisen vastaisuuden historia kulkee käsi kädessä demokratian historian kanssa. Demokratia, kansan valta, on valtiomuoto, jossa kansalainen on samalla kertaa alamainen ja suvereeni passiivinen alamainen yksityishenkilönä ja aktiivinen suvereeni kollektiivina. Niinpä kansalainen, joka omaksuu vain edellisen osan eikä suostu toteuttamaan aktiivista kollektiivista suvereenisuuttaan, joko suljetaan ulos kansasta tai "pakotetaan olemaan vapaa”, niin kuin Jean-Jacques Rousseau asian esitti (Rousseau, 1988, 48). Perinteisesti tämä vapauteen - aktiiviseen kollektiiviseen suvereenisuuteen - pakottava toiminta on ollut kasvatusta. Kasvatus on vuorostaan ymmärretty ennen muuta kurina ja moralisointina. Sen päämääränä on ollut passiivisen ihmisen aktivoiminen eli yksityisen ja eristetyn tietoisuuden taivuttaminen kohti kansan yhteistä ja kollektiivista suvereenia tietoisuutta. Esimerkiksi Rousseau, mutta ei suinkaan yksin hän, piti tätä tietoisuuden taivuttamista demokraattisen valtion ankarimpana koetinkivenä: "Heti kun joku vain sanoo valtion asioista: 'Mitä ne minua liikuttavat?' on valtiota pidettävä häviöön tuomittuna” (emt., 153).

Toisin kuin Kuuselle ja Hautamäelle, Rousseaulle talous ei kuitenkaan kuulunut valtion eli kollektiivisen suvereenisuuden alaan. Antiikin kreikkalaisten tavoin hän piti taloutta orjalle sopivana toimintana, "orjan sanana”. Kuusi sen sijaan tietää, että taloutta on mahdotonta eristää valtion asioista. Valtion asioista on 1900-luvulla tullut nimenomaan valtion taloutta. Olennaista ei kuitenkaan ole enää yksityisen ja eristetyn tietoisuuden taivuttaminen kohti kansan yhteistä ja kollektiivista tietoisuutta. Sillä valtion eli kansan talouden kasvu - sikäli kuin demokratiassa valtiota ei voi erottaa kansasta - ei edellytä kansalaisen tietoisuutta valtion tai kansan asioista. On totta, että hänet on muutettava "aktiiviseksi taloudellisen nousun tavoittelijaksi” (Kuusi 1961, 57), mutta tuo muuttaminen ei tapahdukaan enää kasvatuksen avulla. Sillä kasvatus - kurinpito ja moralisointi - perustuu tietoisuuden taivuttamiseen. Niinpä kasvatuksen sijaan astuu paljaan elämän kontrolli. Kontrolli edeltää tietoisuutta. Se jäsentää elämän kulkua tiedottoman - ennen muuta perinnöllisyyden ja ympäristön - tasolla. Jos kasvatus taivuttaa tietoisuuden, kontrolli organisoi paljaan elämän. ${ }^{2}$ Valta ei kysy enää, "mikä on se kurin muoto ja moraalin sisältö, jonka avulla aktivoin passiivisen yksilön?" Sen sijaan se kysyy, "miten organisoin yksilön perinnöllisyyden ja ympäristön, jotta hänestä tulee aktiivinen?”

Epäilemättä Pekka Kuusen kokonaissuunnitelma on aito kontrollin aikakauden tuote. Tässä mielessä se tarjoaa kansalaisille enemmän tietoisuuden vapautta - toisin sanoen vapautta kurista ja moralisoinnista kuin Antti Hautamäen suunnitelma spontaania yhteiskuntaa varten, siitä huolimatta, että Hautamäki kutsuu yhteiskuntaansa "vapauden valtakunnaksi” (Hautamäki 1993, 169). Sillä Hautamäki ei lakkaa moralisoimasta. Hän moralisoi hyvinvointivaltiota siitä moraalittomuudesta, jonka se muun muassa ylenpalttisen kontrollin takia on saanut aikaan: "Hyvinvointivaltio rapauttaa 
aitoa moraalia" (emt., 136). ${ }^{3}$ Samalla hän ainakin epäsuorasti - moralisoi hyvinvointivaltion aikaansaannoksia, hyvinvointivaltion passiivisia kansalaisia. Hän ei kuitenkaan halua luopua kontrollista. Itse asiassa hän tekee kontrollista sekä paljaan elämän että moraalisuuden kontrollia. Toisin sanoen Hautamäki onnistuu palauttamaan sen, mistä hyvinvointivaltion kontrollin avulla päästiin eroon - nimittäin kurin ja moralisoinnin luopumatta kuitenkaan yksilön paljaan elämän organisoimisesta. Enää tuota organisointia ei kuitenkaan suorita niinkään "kallis, jäykkä ja autoritaarinen" valtio vaan tehokkaan kilpailun periaate. Valtiotakaan ei kuitenkaan tule unohtaa, mutta sen tehtävänä on yhtäältä tehokkaan kilpailun periaatteen palveleminen niin sanottujen kilpailukykypalvelujen muodossa: "Kilpailukykypalvelut tähtäävät osaavan ja työkykyisen väestön luomiseen" (emt., 203). Toisaalta sen tehtävänä on entistä tehokkaammin kontrolloida näiden - sekä muiden valtion tarjoamien - palvelujen käyttäjiä. Näin Kuusen yleistetyn kontrollin yhteiskunta, joka mahdollisti luopumisen tuotantoa jarruttavista kurin ja moralisoinnin periaatteista, saa tehdä tilaa Hautamäen erikoistuneen kontrollin yhteiskunnalle, jossa kuri ja moralisointi asetetaan - "turvallisemman ja sympaattisemman" elämän ohella - tehokkuuden ja kilpailun lisäämisen palvelukseen. ${ }^{4}$

Edellä mainitut erot Kuusen ja Hautamäen suunnitelmien välillä eivät kuitenkaan kätke sitä yhteistä perustaa, jolla näiden kummankin yhteiskuntasuunnittelijan suunnitelma lepää. Tämä perusta on yhteinen vihollinen: passiivisuus. Jos poliittinen viisaus alkaa vihollisen tunnistamisesta, on ilmeistä, että Kuusen ja Hautamäen on oltava selvillä vihaamansa passiivisuuden luonteesta. Toisin kuin Kuusi Hautamäki ei kuitenkaan anna mitään tyhjentävää selvitystä siitä, mitä hän kansalaisen passiivisuudella oikeastaan tarkoittaa. Tästä syystä pyrin vastaamaan passiivisuuden luonnetta koskevaan kysymykseen tarkastelemalla Kuusen 60-luvun sosiaalipolitiikassaan antamaa passiivisen - nähdäkseni yhtä hyvin hyvinvointivaltiolle, spontaanille yhteiskunnalle kuin mille tahansa nykyaikaiselle yhteiskunnalle epäsopivan - kansalaisen esimerkkiä. Tämä esimerkki on Joel Lehtosen Putkinotkon erään hahmon, Juutas Käkriäisen, elämä.

60-luvun sosiaalipolitiikan luvussa "Passiivisen väestön ongelma" Pekka Kuusi lainaa seuraavan katkelman Putkinotkosta:

Juutas nyt on sellainen köntys. On mitä on. Hidas luonteeltaan. Ja itsepäinen se on kuin synti. Ei sitä saa liikkeelle kangella kääntäenkään milloin sille se puuska tulee. Eipä silti, ettei hän tekisi työtäkin, milloin alkaa: silloin se kaivaa yölläkin peltoa ja touhuaa muuta. Mutta se alkaminen on niin vaikeaa.

Ja ne alkamattomuuden puuskat ovat pitkiä. Kestävät joskus kokonaisen vuodenkin. Ja varsinkaan pahoilla ilmoilla ei se tahtoisi vääntäytyä ulos, tuskin niille asioillekaan. Ei, makaa, röhöttää, silloin kuukausittain. Niin kuin karhu talvella. Ei muuta kuin makaa sikeässä unessa... aivan kuin horroksessa. (Lehtonen 1995, 34. $)^{5}$

Tämä on varsin hyvin Juutaksen elämänmuotoa - hänen eetostaan - kuvaava jakso Putkinotkon alusta. Se osoittaa, että Kuusi on tietoinen Juutaksen todellisesta luonteesta. Toisin sanoen hän haluaa sulkea Juutaksen ulos sellaisena kuin hän on, eikä siitä syystä, ettei ymmärtänyt tämän todellista luonnetta.

Mikä siis on Juutaksen todellinen luonne? Edellä lainattu teksti kertoo melkein kaiken. On kuitenkin tarkasteltava lähemmin, mitä tuo teksti oikeastaan sanoo. Ensinnäkin se kertoo, että Juutas on itsepäinen. Mitä merkitsee itsepäisyys? Itsepäinen henkilö ei ajattele tai käyttäydy muiden ihmisten odottamalla tavalla. Tähän on olemassa kaksi perussyytä. Yhtäältä puhdas itsepäisyys. Kyse on itsepäisyydestä ilman syytä, järjettömästä itsepäisyydestä. Toisaalta henkilö 
voi olla käyttäytymättä muiden odottamalla tavalla, koska hän ei näe mitään syytä järkeä - käyttäytyä toisin kuin sattuu käyttäytymään. Näyttää siltä, että Juutas kuuluu tähän toiseen kategoriaan: "Hän on yleensä vasten kaikkea, mitä hän ei ole itse ensin ajatellut" (emt., 62).

Immanuel Kantin mukaan tällainen itsepäisyys merkitsee valistusta: "Maksiimi, jonka mukaan on aina ajateltava itse, merkitsee valistusta" (Kant 1995a, 104). Erkki Tuomiojan mukaan Kuusi kuuluu valistuksen pitkään traditioon, mutta hän ei tarkoitakaan valistusta kantilaisittain (Tuomioja 1996, 343). Järki on kyllä Kuusen ohjelman johtava periaate, mutta tämä järki ei ole henkilön omaa järkeä vaan valtion tai "taloudelliseen kasvuun pyrkivän yhteiskunnan” järkeä. Kantin mukaan tällainen järjestelmän järjen seuraaminen tai "toisen johtamana" oleminen tarkoittaa alaikäisyyttä - epäsopivaa kansalaisuutta - ja niinpä henkilö, joka ei Juutaksen tavoin ole itsepäinen, eli joka ei ajattele ensin itse, on alaikäinen: "Alaikäisyys on kyvyttömyyttä käyttää omaa järkeään ilman toisen johdatusta." (Kant 1995b, 77.) Toisin sanoen, jos hyväksytään Kantin määritelmä, Juutas merkitsee emansipaation mahdollisuutta kuusilaisen hyvinvointivaltion aiheuttamasta alaikäisyydestä. Sillä vaikka Kuusen valtion lähtökohtana on kansalainen, se haluaa kuitenkin alistaa kaikki välittömästi jatkuvalle taloudelliselle liikekannallepanolle, kun taas Juutas on hahmo, joka kyseenalaistaa tämän liikekannallepanon.

Voidaanko Juutas näin ollen määritellä avoimen yhteiskunnan kriittiseksi kansalaiseksi - esimerkiksi jonkinlaiseksi Hautamäen "vapauden valtakunnan" kansalaiseksi vastakohtanaan Kuusen suljetun ja totalitaarisen yhteiskunnan aivopesty kansalainen? Ei. Kyse on aivan muusta. Perustavin vastakohta ei suinkaan ole avoimen ja suljetun yhteiskunnan tai kriittisen ja reflektiivisen ja epäkriittisen ja epäreflektiivisen kansalaisen välillä. Sillä Kantin valistuneen kansalaisen kritiikki on julkista ja näin - ainakin periaatteessa - rakentavaa. Tästä syystä kantilainen järkeily voi aivan hyvin kuulua Kuusen kantakansalaisen ominaisuuksiin. Juutasta ei olekaan suljettu Kuusen hyvinvointivaltiosta siitä syystä, että hän haluaa miettiä asiaa ensin itse. Pikemminkin hänet suljetaan ulos siksi, että hänen ajattelunsa - hänen yksityinen kriittinen asenteensa - on kasvusuuntautuneen yhteiskunnan kannalta tuottamatonta. Hän ei hyväksy, mitä muut sanovat, ilman huolellista reflektiota, mutta hänen reflektionsa ei johda mihinkään - ei edes hänen itsensä kohdalla. Mitä tahansa tapahtuu, Juutas "on mitä on".

Tästä syystä on tutustuttava toiseen Juutaksen elämän johtavaan eetokseen. Tämä on vapauden eetos. Juutas on äärimmäisen herkkä persoonallisen vapautensa suhteen ja esimerkiksi toiselle tehtyä työtä hän pitää suoralta kädeltä orjuutuksena. Jopa itselle tehty työ on orjuutusta, jos se tapahtuu vastentahtoisesti. Silloin häntä ei saa liikkeelle "kangella kääntäenkään”. Tämän takia Juutaksen elämänmuoto ei muistuta niinkään kantilaisen valistuneen ihmisen elämää vaan pikemminkin antiikin kyynikkojen elämänmuotoa. Hän ei halua alistaa itseään epäluonnollisten tapojen ja kulttuurin vaatimuksiin vaan toimii luontonsa mukaan, esimerkiksi "tekee tarpeensa" missä haluaa ja näyttää seuraavan muutenkin kyynikkojen keskeisiä periaatteita. Hänhän harrastaa, etenkin kylille mennessään, suoraa ja peittelemätöntä puhetta (parresia) ja arvostaa yli kaiken itseriittoisuutta (autarkeia) - eikä häntä voida syyttää liiasta oppineisuudestakaan, joka monien kyynikoiden mukaan johtaa vain turhaan sanahelinään. Onko Juutas näin ollen suljettu ulos Kuusen hyvinvointivaltiosta epäsosiaalisuutensa vuoksi? Mahdollisesti. Toisaalta on huomattava, että kyynikoiden epäsosiaalisuus oli jotakin aivan muuta kuin Juutaksen epäsosiaalisuus. Kyynikoille vapaus tapojen kahleista oli elämää ohjaava periaate, "elämänkäytännön johdonmukainen metodi" - kuten asia voitaisiin Max Weberin termein esittää (Weber 1990, 85-94).

Nähdäkseni Juutaksen elämänmuodon vapaus on tavallaan vielä radikaalimpaa. Se on vapautta jopa "elämänkäytännön joh- 
donmukaisesta metodista”. Sillä Juutas ei ole Kuusen hyvinvointivaltion kantakansalaisen vastakohta itsepäisyytensä eikä henkilökohtaisen vapaudenkaipuunsa takia, vaan $e i$ metodologisen elämänmuotonsa takia. Jopa hänen passiivisuutensa on ei-metodologista passiivisuutta sikäli kuin Juutas on myös aktiivinen, jopa hyperaktiivinen niin kuin Lehtonen kuvaa: "milloin alkaa, silloin se kaivaa yölläkin peltoa ja touhuaa muuta". Kuusen hyvinvointivaltion - kasvusuuntautuneen yhteiskunnan - näkökulmasta Juutaksen aktiivisuus on kuitenkin epäjohdonmukaista. Hän ei aloita silloin kun hänen pitäisi aloittaa vaan ikään kuin miten sattuu, kontingentisti. Kontingenssi sinänsä ei kuitenkaan ole kasvusuuntautuneelle yhteiskunnalle vahingollista, päinvastoin. Taloudellisen kasvun näkökulmasta vakaa yhteiskunta on kuollut yhteiskunta. Tästä syystä valta moderneissa dynaamisissa yhteiskunnissa - yhtä lailla hyvinvointiyhteiskunnissa kuin kilpailuyhteiskunnissakin - ei yritä estää kontingenssia vaan tuottaa ja hallita sitä, luoda sitä ja käyttää sitä tiettyihin päämääriin. Filosofisemmin ilmaistuna tämä merkitsee potentiaalin organisoimista.

Kontingenssi on vallan tuotos. Se syntyy, kun valta erottaa potentiaalisuuden teosta. Vastaavasti kaikesta toiminnasta tulee enemmän tai vähemmän kontingenttia. Mitä tahansa voi tapahtua. Tämä on Thomas Hobbesin kuuluisan fiktion - "kaikkien sota kaikkia vastaan" - alkuperäinen merkitys ja modernin valtion legitimaation perusta. Valtio takaa, että mitä tahansa ei tapahdu. Se organisoi potentiaalisuuden. On totta, että hobbesilainen valtio organisoi vain negatiiviset potentiaalisuudet monopolisoiden väkivallan, mutta kuusilaisen hyvinvointivaltion ansioksi voidaankin laskea sekä negatiivisten että positiivisten - tuottavien - potentiaalisuuksien organisointi. Ja juuri tämä kaikkien potentiaalisuuksien organisointi tekee ymmärrettäväksi, miksi Juutas on suljettava ulos Kuusen hyvinvointivaltiosta. Sillä ei ole mitään tekemistä sen kanssa, että Juutas ajattelee itse tai varjelee henkilökohtaista vapauttaan - edes passivisuus ei sinänsä ole todellinen syy. Pikemminkin se liittyy siihen tosiasiaan, että Juutas "on mitä on” eli että hän aktualisoi kaikki potentiaalit jokaisessa teossa, eikä valta voi näin ollen organisoida hänen elämäänsä. Juutaksen potentiaalisuus, hänen olemuksensa, lepää hänen aktuaalisessa elämässään, hänen olemassaolossaan. Valta ei kykene antamaan muotoa hänen elämälleen - organisoimaan sitä - koska ei ole olemassa elämän ja sen muodon erottavaa rajaa, kontingenssia. Juutaksen elämänmuoto ei ole muoto, joka on annettu elämälle vaan pikemminkin elämä, joka on erottamaton muodostaan.

Tästä näkökulmasta Juutaksen elämänmuoto ei ole kontingentti vaan täydellisen johdonmukainen. Se on johdonmukainen itsensä kanssa. Juutas ei ole jotakin muuta kuin mitä hän on. Hän on mitä on. Tästä syystä nimenomaan Kuusen hyvinvointivaltio-ohjelma - kuten Hautamäen spontaanin yhteiskunnan ohjelma -, joka sanoo ottavansa lähtökohdakseen kansalaisen parhaan, näyttää olevan epäjohdonmukainen. Se pyrkii tekemään Juutaksesta jotakin muuta kuin mitä hän on eristämällä hänen potentiaalisuutensa hänen teoistaan. Tämä elämän ja sen muodon eristäminen mahdollistaa potentiaalisuuden organisoinnin - viimekädessä sen suurimman täydellisyyden eli omnipotenssin pisteeseen saakka. ${ }^{6}$ Jos kuitenkin uskotaan Aristotelesta, joka kirjoittaa että nautinto on se, jonka muoto on "millä hetkellä tahansa täydellinen" (Aristoteles 1989, 1174b-1175a22), omnipotenssi ei ole kansalaisen paras vaan hänen huonoimpansa. Omnipotenssi - absoluuttinen tyytymättömyys - on tuskan korkein muoto. Sikäli kuin nautinto ja tyydytys eli täysi elämä ovat kansalaisen paras eivätkä tuska, Kuusen hyvinvointivaltio on hyvinvointivaltion vastakohta. Se ei anna kansalaistensa olla tyytyväisiä vaan tuottaa tietoisesti ja lakkaamatta tyytymättömyyttä eli nautinnosta eristettyjä potentiaalisuuksia. ${ }^{7}$ Todellinen hyvinvointivaltio - valtio, jonka päämääränä on kansalaisen paras - ei estä ihmistä olemasta se mikä hän on vaan antaa hänen nauttia elämästään. Se ei eristä hänen 
elämäänsä, paljasta elämää ja inhimillistä potenssia, muodosta ja toiminnasta. Päinvastoin, eräänlaisena ylivaltiona, valtiona ilman kaunaa ja resentimenttiä ${ }^{8}$, se pyrkii luomaan - vaikka tämä ei suinkaan ole mikään helppo tehtävä - lukemattomia potenssin ja aktin väyliä ja yhdistämisen tapoja. Se pyrkii luomaan tilan onnellisuudelle. Lain termein sanoen, se ei luo lakia estääkseen toimintaa eikä se tuhoa lakia sikäli kuin lain tuhoaminen merkitsee inhimillisten potentiaalien tuhoamista. Ennemminkin se pyrkii täydellistämään lain - ja niin kuin Paavali ymmärsi, tämä merkitsee rakkautta.

\section{vi i t te e t}

1. Ernst Jünger, tämä Hitleriä 1920-luvulla ihaillut ensimmäisen ja toisen maailmansodan veteraani, oli se, joka ensimmäisenä käsitti täysin kaikkien jatkuvan mobilisaation - "totaalisen mobilisaation" merkityksen. Hänen mobilisaationsa oli totaalista kuitenkin siitä syystä, että kansakunnan kaikki - eritoten taloudelliset pyrkimykset oli tavalla tai toisella valjastettu sotilasoperaatioiden palvelukseen. Kuusen kaikkien jatkuva mobilisaatio on totaalista, koska jopa sotateollisuus on tavalla tai toisella valjastettu taloudellisen kasvun palvelukseen. Toisin sanoen, jos Jünger puhui totaalisesta mobilisaatiosta sotamenestyksen nimissä, Kuusi - joka entisenä fasistisen nuorisojärjestön Sinimustien aktiivijäsenenä saattoi hyvinkin olla tietoinen Jüngerin kirjoituksista pyrki siihen taloudellisen kasvun nimissä. Jüngerin argumentista ks. Jünger 1993. Kuusen poliittisesta elämäkerrasta ks. Tuomioja 1996.

2. Kasvatuksen tulemisesta paljaan elämän eli perinnöllisyyden ja ympäristön kontrolliksi ks. Ojakangas 1997, 109-284.

3. Hautamäen spontaania vastuullisuutta ehkäisevän hyvinvointivaltion "laajentuneen koneiston" moraalinen kritiikki on kuitenkin jossain määrin epäjohdonmukaista sikäli kuin hän samalla väittää, että tuon koneiston tuotokset "kaikesta massiivisuudestaan huolimatta" vain "hipaisevat ihmisen elämää” (Hautamäki 1993, 143). Kenties hyvinvointivaltion suurin synti ei olekaan siinä, että se pitää liikaa huolta kansalaisistaan, vaan päinvastoin siinä, että se toimii eräänlaisella huolettomuuden periaatteella - se jakaa hyvinvointia välinpitämättömästi.

4. Näyttää siltä, että totalitarismistakin moitittu Kuusi korostaa enemmän erilaisten etujen yhteensovittamista politiikan avulla kuin Hautamäki, joka mielellään korvaisi tällaisen etujen yhteensovittamisen - "politikoinnin ja etujen metsästyksen" ilmeisestikin kaikesta poliittisesta vapaalla moraalilla, jonka kaksi peruspilaria ovat omavastuu ja yhteisölliset arvot. (Ks. erit. Hautamäki 1993, lopputeesit, 242-243).

5. Lainattu teoksessa Kuusi 1961, 54.

6. Hautamäen termein tämä tarkoittaa "mahdollisuuksien maksimointia", jonka vain spontaani yhteiskunta hänen mukaansa kykenee tuottamaan (Hautamäki 1993, 172).

7. Kuusen mukaan taloudelliseen kasvuun pyrkivällä yhteiskunnalla ei ole varaa siihen, että ihmiset eivät pyri "kulutustasoaan kohottamaan" vaan "jättäytyvät oloihinsa"; "vähään tyytyvät maan hiljaiset eivät ole nyky-yhteiskunnassa enää kantakansalaisia..." (Kuusi 1961, 59).

8. Siitä millainen tuo valtio voisi olla, me saamme vihjeen keneltäpä muultakaan kuin Friedrich Nietzscheltä (1969, 65): "Ei olisi mahdotonta ajatella sellaista yhteiskunnan vallantietoisuutta jonka vallitessa se voisi suoda itselleen ylhäisimmän ylellisyyden joka on sitä varten olemassa - jättää vahingoittajansa rankaisematta. 'Mitä minä oikeastaan välitänkään loisistani?' voisi se silloin sanoa. 'Eläkööt ja menestykööt! siihen minä olen kyllin voimakas!'... Oikeudenmukaisuus joka alkoi siitä että 'kaikki on maksettava, kaikki täytyy maksaa' päätyy siihen ettei olla mitään huomaavinaan ja päästetään maksukyvytön vapaaksi - se päättyy niin kuin kaikki hyvät asiat maan päällä siten että se kumoaa itsensä." Kun vielä lisätään, ettei tuollainen ansioihin nähden täysin epäoikeudenmukainen valtio valtio kumottuna eli täydellisenä - jätä vain rankaisematta vaan omaa sen "lah- 
joittajan hyveen", josta Nietzsche Zarathustran suulla puhuu ja jota luonnehtii "kyltymätön lahjoittamisen-tahto", lähes-

Aristoteles, Nikomakhoksen etiikka. Gaudeamus, 1989.

Hautamäki, Antti: "Spontaaniin yhteiskuntaan - hyvinvointia ilman valtiota." Teoksessa Andersson ym., Hyvinvointivaltio ristiaallokossa. WSOY, 1993.

0
0

Jünger, Ernst: "Total mobilization". Teoksessa Richard Wolin, The Heidegger Controversy. MIT Press, 1993.

Kant, Immanuel: "Mitä on suunnistautuminen ajattelussa." Teoksessa Koivisto ym., (toim.), Mitä on valistus? Vastapaino, 1995a.

Kant, Immanuel: "Vastaus kysymykseen, mitä on valistus?" Teoksessa Koivisto ym., (toim.), Mitä on valistus? Vastapaino, 1995b. utopiaako? Kenties vain ohut kalvo erottaa aktuaalisen tilamme tuosta valtiollisen täydellisyyden tilasta...

\section{K I R J A L LIS U U S}

Kuusi, Pekka: 6o-luvun sosiaalipolitiikka. WSOY, 1961.

Lehtonen, Joel: Putkinotko. SKS, 1995.

Nietzsche, Friedrich: Moraalin alkuperästä. Otava, 1969.

Ojakangas, Mika: Lapsuus ja auktoriteetti. Pedagogisen vallan historia Snellmanista Koskenniemeen. Tutkijaliitto, 1997.

Rousseau, Jean-Jacques: Yhteiskuntasopimuksesta. Karisto, 1988.

Tuomioja, Erkki: Pekka Kuusi - alkoholipoliitikko, sosiaalipoliitikko, ihmiskuntapolititkko. Tammi, 1996.

Weber, Max: Protestanttinen etiikka ja kapitalismin henki. WSOY, 1990. 